\title{
Determination of Young's Modulus by Specific Vibration of Basalt and Diabase
}

\author{
Osvail André Quaglio $\mathbb{D}^{1},{ }^{1}$ José Margarida da Silva, ${ }^{2}$ Edmo da Cunha Rodovalho, ${ }^{1}$ \\ and Leandro de Vilhena Costa ${ }^{2}$ \\ ${ }^{1}$ Federal University of Alfenas, Department of Mining Engineering, Rod. José Aurélio Vilela, 11999, BR $267 \mathrm{~km} 533$, \\ Postal Code 37715-400, Poços de Caldas, Minas Gerais State, Brazil \\ ${ }^{2}$ Federal University of Ouro Preto, Programa de Pós-Graduação em Engenharia Mineral (PPGEM), Morro do Cruzeiro Campus, \\ Postal Code 35400-000, Ouro Preto, Minas Gerais State, Brazil \\ Correspondence should be addressed to Osvail André Quaglio; osvail.quaglio@unifal-mg.edu.br
}

Received 10 December 2019; Accepted 13 February 2020; Published 14 April 2020

Academic Editor: Marco Cannas

Copyright (C) 2020 Osvail André Quaglio et al. This is an open access article distributed under the Creative Commons Attribution License, which permits unrestricted use, distribution, and reproduction in any medium, provided the original work is properly cited.

\begin{abstract}
The elasticity is an important parameter for the evaluation of the mechanical behavior of a rock mass and a fundamental factor in the definition of the resistance characteristics, stability, and blastability in rock blasts, and it is an important parameter for the blastability equations like the Kuz-Ram method. This paper presents a comparison of the Uniaxial Compression Method (UCM) and the Impulse Excitation Technique (IET) in determining Young's modulus. The IET is a static and nondestructive dynamic method of characterizing mechanical parameters of materials, while the UCM is a quasistatic and destructive method. We determined Young's modulus of samples from nine basalt and diabase mines used as aggregates in the construction industry. Young's modulus was determined by the acoustic response due to longitudinal oscillations caused by a mechanical impulse (IET) in the Sonelastic equipment and the stress-strain curve (UCM). Young's modulus values showed high repeatability and agreed with those reported in the literature for the same material. The work shows that the solnelastic is an innovate equipment and elucidated advantages of IET in comparison to the UCM such as shorter execution time, greater safety, and a lower cost ranging from $11.5 \%$ to $22.5 \%$ of the UCM.
\end{abstract}

\section{Introduction}

The deformability is important for the evaluation of the mechanical behavior of a rocky massif [1] as it is a fundamental criterium for the definition of the resistance and blastability in rock blasts. Young's modulus and Poisson's coefficient characterize the mechanical behavior of a rock mass due to several simulation scenarios when applying tension variations and the use of explosives for blasting or fragmentation material in quarries. Young's modulus is one of the most important mechanical parameters for evaluating the mechanical stability of a material [2] used in established methods such as the Kuz-Ram and KCO models.

The blastability index is the fragmentation capacity of a rock mass that is determined by the granulometric distribution of the blasted material, once the variables of the blast plane are defined. The Kuz-Ram method can be used to calculate the blastability index based on Young's modulus [3-6].

Young's modulus is influenced by characteristics of the rock such as discontinuities, petrographic structure, degree of weathering and alteration, void index and porosity, and elastic and plastic properties [1]. Static or quasistatic methods as the uniaxial and triaxial compression are commonly used to determine the abovementioned properties of materials. However, those methods are destructive, rendering the test pieces unusable [2].

Alternatively, the measurement of the natural frequency of a material using the forced resonant frequency can be used to determine dynamic Young's modulus, but this method is 
not routinely used in Brazil [7]. According to Bezerra [7], the stress-strain curve presents a nonlinear behavior for concrete, which hinders the accuracy of the values of static Young's modulus. The dynamic methods, which do not directly interfere in the sample because it does not exert tensions that cause changes in the physical behavior of the sample, provide more precise results. In addition, the use of dynamic Young's modulus is more appropriate to structures subjected to impact loads such as rock blast works.

Garaygordóbil [8] reported that the stress-strain curve does not present a linear behavior disturbing the calculation of a single value for Young's modulus; thus, nondestructive methods, which do not interfere directly with the sample, provide more accurate values. Carrasco et al. [9] found the IET to be a promising alternative for estimating Young's modulus of Brazilian wood. Only $2.46 \%$ of their predicted values were different of the estimated modules using a significance level of $95 \%$.

The IET principle is to measure the resonance frequencies by impulse indifferent vibrational modes: flexional, torsional, and longitudinal. These vibrations are detected by an acoustic microphone and then converted to an electrical signal, recorded as a function of time. The signal is represented by the fast Fourrier transform as a function of the resonance frequencies of the sample. The elasticity constants of materials are calculated by the resonance frequency, density or mass, and dimensions of the sample [10].

The IET is a quick and effective method for measuring Young's modulus in undamaged samples [11]. Compared to the standard mechanical characterization, the IET is less affected by the typical heterogeneity of thick composite laminates and provides more repeatable results based on local strain measurements, but yields slightly larger values, probably because of the detrimental effect of the deformation rate [12].

The prediction of which resonances will be observed in a measurement is straightforward using the resonance eigenvalues and eigenvectors. A sinusoidal excitation is applied in some point on the sample, the response is measured in other point, and the process can be repeated for many frequencies [13].
Table 1 shows a comparison between quasistatic and dynamic methods [14]. Therefore, the dynamic method presents advantages over the traditional quasistatic method because the determination is faster, it can be applied to several types of materials, the sample is not destroyed, the influence of the temperature in the elasticity can be determined, and it has less uncertainty especially when applied to determine the blastability of a rock [14]. The IET can also potentially be used to determine the modulus of dynamic elasticity in preventive maintenance and in the impact assessment of concrete structures that are subject to dynamic loads [15].

The IET is a dynamic method that uses the natural frequency of specific vibrations of each material [16] and characterizes Young's modulus and the damping by the acoustic response after a slight inserted mechanical impulse. Upon receiving a defined stimulation, the material generates elastic, transverse, and twisted longitudinal oscillations. When the yielded wavelength corresponds to the specific dimensions of the sample, there is a resonance effect with large amplitudes of oscillation [17]. The acoustic response is specific of each material and depends on the natural vibration frequencies of each material, which are proportional to Young's modulus and attenuation rate proportional to damping [16]. The time to obtain the natural frequency values is a fraction of a second. The acoustic response is picked up by a receiver in the opposite portion of the stimulus ( $1^{\circ}$-Figure 1$)$, the acoustic response is converted in an amplitude graph $\left(2^{\circ}\right.$ and $3^{\circ}$-Figure 1$)$ by a specific software, and Young's modulus is determined ( $4^{\circ}$-Figure 1$)$.

The model for calculating Young's modulus from flexural vibration for circular section specimens is described below, according to ASTM E-1876 [18], E-1875 [19], and C215 [14, 20].

$$
E=1.6067\left(\frac{L^{3}}{D^{4}}\right)\left(m f_{f}^{2}\right) T_{1}^{\prime}
$$

where $D$ is the diameter $(\mathrm{mm}), L$ the length $(\mathrm{mm}), m$ the mass $(\mathrm{g}), f_{\mathrm{f}}$ is the fundamental flexional resonance frequency, and $T_{1}$ is a correction factor for the fundamental flexion mode given by

$$
\begin{aligned}
\hat{T}_{1}= & +4.939\left(1+0.0752 \mu+0.8109 \mu^{2}\right)\left(\frac{D}{L}\right)^{2}-0.4883\left(\frac{D}{L}\right)^{4} \\
& -\left[\frac{4.6911\left(1+0.2023 \mu+2.173 \mu^{2}\right)(D / L)^{4}}{1.000+4.7541\left(1+0.1408 \mu+1.536 \mu^{2}\right)(D / L)^{2}}\right],
\end{aligned}
$$

where $\mu$ is Poisson's ratio.
The calculation of the uncertainty for Young's modulus in the flexional mode is given by

$$
\Delta E=\frac{2 E}{1.73205} \sqrt{\left(3 \frac{\Delta L}{L}\right)^{2}+\left(4 \frac{\Delta D}{D}\right)^{2}+\left(\frac{\Delta m}{m}\right)^{2}+\left(2 \frac{\Delta f_{f}}{f_{f}}\right)^{2}+\left(\frac{1}{40} \frac{\Delta \mu^{*}}{\mu}\right)^{2}}
$$


TABle 1: Comparison between quasistatic and dynamic methods [14].

\begin{tabular}{lccccc}
\hline & Destructive test & Uncertainty measurement & Measurement time & Characterizable samples & $\begin{array}{c}\text { Measures as a function of } \\
\text { temperature }\end{array}$ \\
\hline Quasistatic & Yes & $15 \%$ or more & ${ }^{* *}$ & Mainly metals & Hard \\
Dynamic & No & $<2 \%$ & Seconds & Any solid material & Easy \\
\hline
\end{tabular}

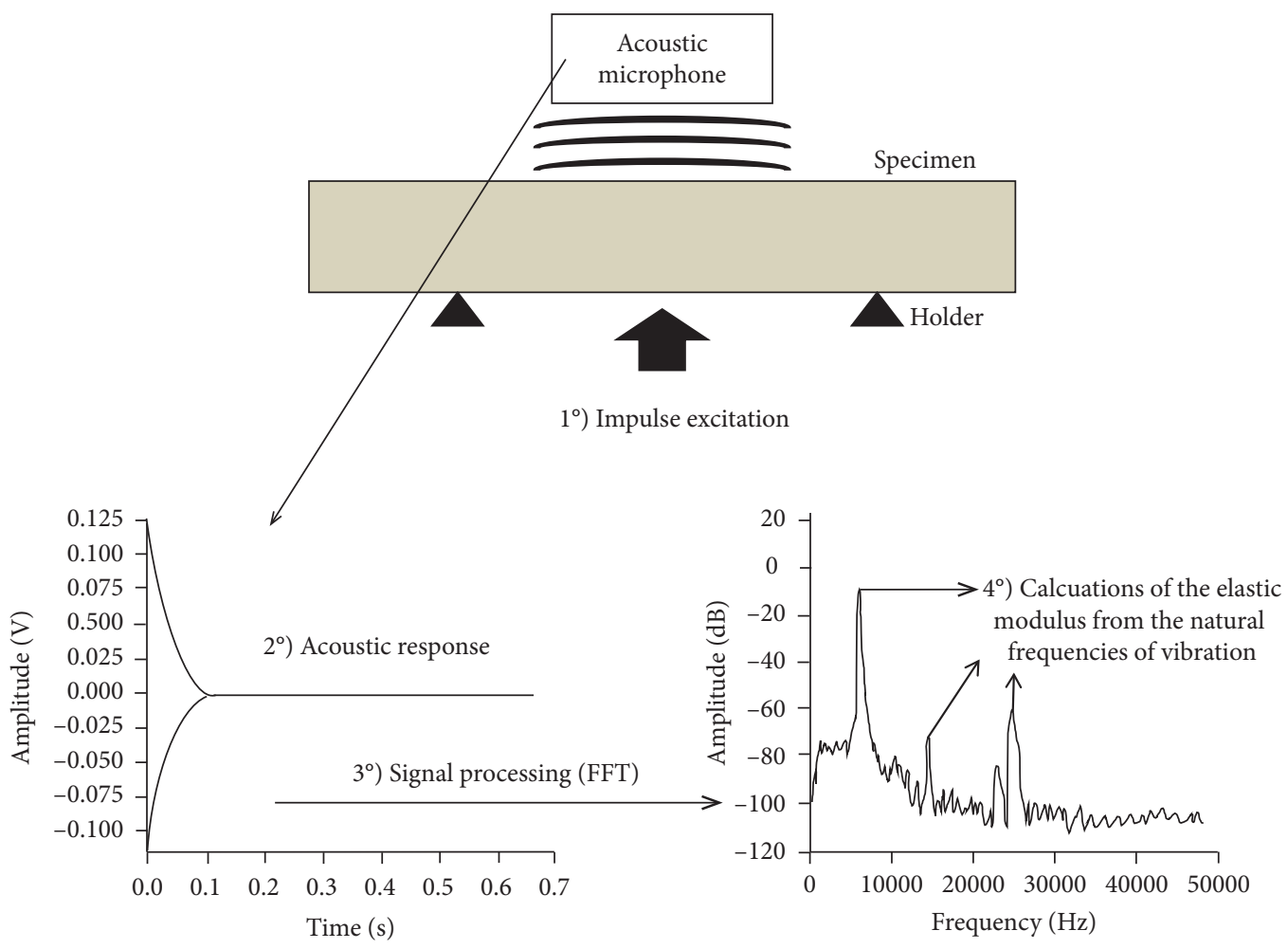

FIGURE 1: Determination of Young's modulus by the Impulse Excitation Technique [16].

If the $L / D$ ratio $\geq 20$, the correction factor $T_{1}^{\prime}$ can be simplified to

$$
T_{1}=\left[1,000+4,939\left(\frac{D}{L}\right)^{2}\right] .
$$

If the ratio $L / D<20$ and Poisson's coefficient is known, then $T_{1}^{\prime}$ can be calculated by equation 2 . If $L / D<20$ and Poisson's coefficient is unknown, then the iterative process shown should be used.

The uniaxial compression method consists of assembling an upper and lower CAP sample set with lateral and axial extensometer, so the set is placed on the pedestal, and the load cell is approximate until the upper cap. Then, a uniaxial load is applied at a constant loading or deformation rate, defined so that the loading time of the test is between 5 and $15 \mathrm{~min}$. Unloading and loading can be performed to obtain the curves of stress-strain.

With the data, it is possible to calculate Young's modulus:

$$
E_{u}=\frac{\Delta \sigma_{a}^{u}}{\Delta \varepsilon_{a}^{u}}
$$

where $\Delta \sigma_{a}^{u}$ is the variation of uniaxial tension and $\Delta \varepsilon_{a}^{u}$ is the variation of deformation on generated line.
The present work aims to compare IET and UCM to obtain Young's modulus of samples of a rock mass in terms of results, run time, sample preservation, safety, and costs.

\section{Methods}

The samples were randomly collected in five different quarries, EX, FV, and SA of basalt and NO and MG of diabase. The specimens of rock were prepared for each quarry using a HILTI DD200 drill, with a $50 \mathrm{~mm}$ diameter. After sachets, each material was sawn to obtain cylindrical specimens with the length $(L)$ ranging between 2 and 3 times the diameter (D), according to the American Society norms for Testing and Materials-ASTMD 2938-95 [21] and ASTM D4543-01 [22]. The specimens were dried in an electric oven for $4 \mathrm{~h}$ at $110^{\circ} \mathrm{C}$ and weighed. Table 2 shows the weight and density of the specimens.

The elasticity modulus was determined by the IET in the Sonelastic equipment according to the norms of the International Society for Rock Mechanics (ISRM) [23], in the ATCP Engenharia Física, in Ribeirão Preto city. The equipment configuration was PC-based.

To perform the test, the nodal points were marked at a distance of $0.244 \mathrm{~L}$ from each end of the sample for support 
TABLE 2: Dimensions of the specimens.

\begin{tabular}{lccccc}
\hline Mine & Sample & $\mathrm{L}(\mathrm{mm}) \pm 0.05$ & $\mathrm{D}(\mathrm{mm}) \pm 0.05$ & Mass $(\mathrm{g}) \pm 0.01$ & Density $\left(\mathrm{g} / \mathrm{cm}^{3}\right)$ \\
\hline \multirow{2}{*}{ EX } & 1 & 142.00 & 49.15 & 823.94 & 809.17 \\
\\
NO & 2 & 142.00 & 49.10 & 766.90 & 3.06 \\
& 1 & 142.00 & 49.15 & 815.19 & 2.85 \\
FV & 2 & 142.00 & 49.15 & 756.59 & 3.03 \\
& 2 & 127.00 & 50.50 & 744.36 & 2.97 \\
SA & 3 & 128.00 & 50.40 & 765.17 & 2.91 \\
MG & 1 & 130.00 & 50.60 & 751.65 & 3.00 \\
\hline
\end{tabular}

in the equipment, where $L$ is the sample length [24]. These positions correspond to the sample nodal lines referring to the flexural fundamental vibration mode and allows the free vibration of the impulse excitation. The acoustic response pickup was positioned at the center of the cylindrical sample and the pulsating point (impact point) at the opposite side (Figure 2). The software was fed by the physical data depicted in Table 2 (mass, length, and diameter). Table 3 shows the technical characteristics of the acoustic microphone used.

After the preparation and positioning of the specimen, the values were measured in each sample. The data were then captured in the software, and the frequency spectrum was preprocessed. Through the preprocessed spectrum, the process to obtain Young's modules was performed, choosing the largest amplitudes with care, so as to eliminate the harmonic peaks.

For uniaxial compression tests, the same samples as the IET test were used. The press used was a $2,000 \mathrm{kN}$ EMIC DL3000 load capacity, with a dual configuration electric strain gauge, with independent sensors for measuring on either side of the specimen and equalizing box to obtain the average strain signal with a measuring range from 0.00001 to $2.50000 \mathrm{~mm}$.

The tests were performed in three loading and unloading steps up to $18 \mathrm{kN}$ and then broken. Young's modulus values were obtained by the stress $x$ strain curve generated by the UCM tests. Figure 3 shows the stress $x$ strain curves for sample EX1, where UCM 1, UCM 2, and UCM 3 are, respectively, the charging 1,2 , and 3 .

The results of both tests were compared by Young's modulus values, costs, and test time between IET and UCM.

\section{Results and Discussion}

Table 4 shows the values of Young's modulus determined by IET and UCM, their standard deviation, and the time cycle of each test using the IET. The values of Young's modulus yielded by the UCM were obtained by averaging three stress-strain curves obtained in the loading and unloading of samples (E1, E2, and E3), and those yielded by the IET are an average of three measurements. For IET Young's modulus, Poisson's ratio of $0.25 \pm 0.25$ was used for the $\Delta E$ calculation (Equation 3 ) with the sake of covering all possible Poisson's ratios (unknown values). The large variation in the Poisson's ratio uncertainty has

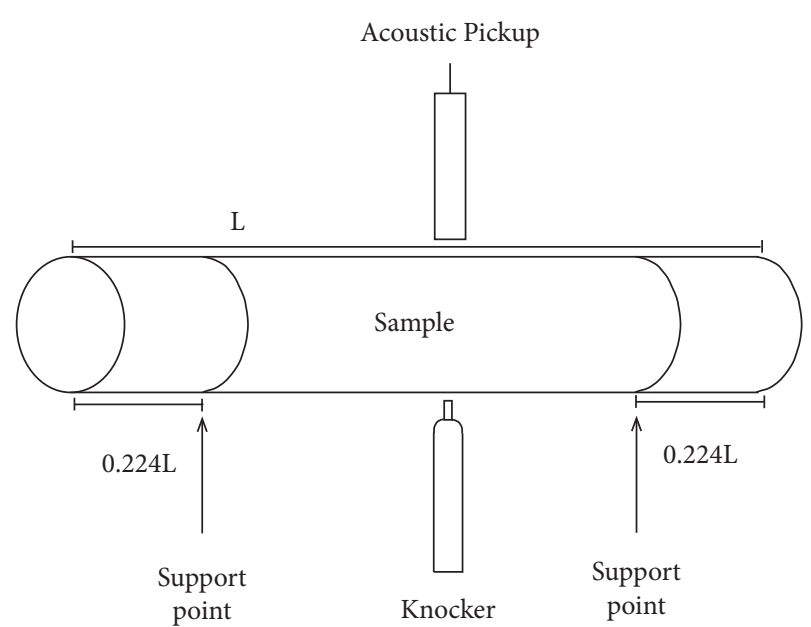

FIgUre 2: Detail of the positioning of the test sample.

TABLE 3: Technical characteristics of the acoustic microphone used.

\begin{tabular}{lc}
\hline Pickup technical specifications & \\
\hline Transducer element & Dedicated electret \\
Frequency range & From $20 \mathrm{~Hz}$ to $96 \mathrm{kHz}$ \\
Sensitivity & $-36 \pm 4 \mathrm{~dB}(0 \mathrm{~dB}=1 \mathrm{~V} / \mathrm{Pa})$ \\
Directivity & Unidirectional \\
Signal to noise ratio (S/N) & $\left(-12 \mathrm{~dB}\right.$ in $\left.180^{\circ} e 1 \mathrm{kHz}\right)$ \\
$\begin{array}{l}\text { Supply voltage } \\
\text { Impedance }\end{array}$ & $60 \mathrm{dBA}$ \\
$\begin{array}{l}\text { Max. Dimensions } \varnothing \times \mathrm{A} \\
\text { (without base) }\end{array}$ & $680 \mathrm{~W}$ \\
$\begin{array}{l}\text { Max. Dimensions } \varnothing \times \mathrm{A} \\
\text { (with base) }\end{array}$ & $20 \times 138 \mathrm{~mm}$ \\
Weight & $63 \times 150 \mathrm{~mm}$ \\
Connection & $110 \mathrm{~g}$ \\
\hline
\end{tabular}

contributed to the larger standard deviations in Young's modulus determination yielded by the IET method compared to the UCM one (Table 4).

The average values of Young's modulus obtained by IET and UMC are very close. The error showed in Table 4 assumes that the elasticity yielded by UCM is real, measuring how far the IET values are from the UCM ones. This error varied from 1 to $12 \%$, indicating that the values yielded by the IET can represent Young's modulus of the analyzed samples.

An advantage of IET is the shorter run time of the assay. The average time interval between two measurements was 


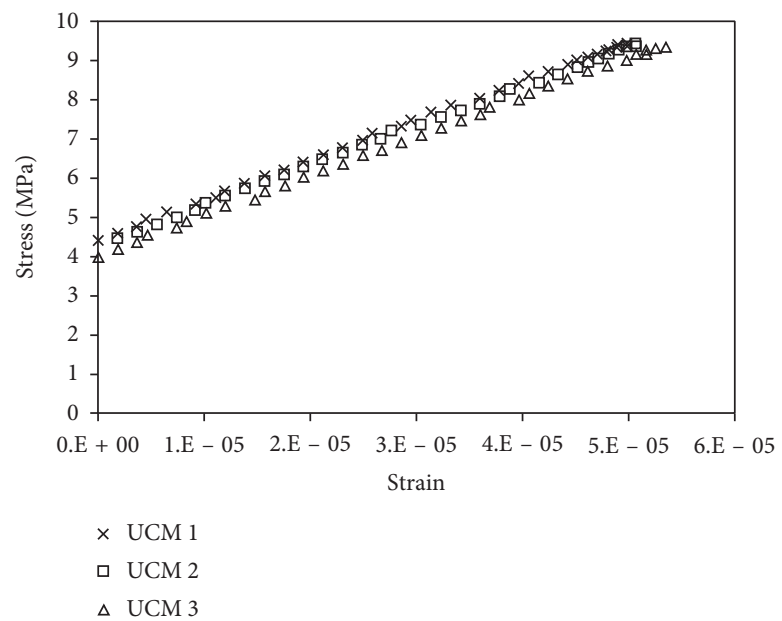

FIgURE 3: Stress-strain curve of sample EX1 for 3-load uniaxial compression test in EX1.

TABLE 4: Young's modulus yielded by IET and UCM.

\begin{tabular}{|c|c|c|c|c|c|c|}
\hline \multicolumn{7}{|c|}{ Young's modulus (GPa) } \\
\hline \multirow{2}{*}{ Sample } & \multicolumn{2}{|r|}{ UCM } & \multicolumn{3}{|c|}{ IET } & \multirow[t]{2}{*}{ Error $(\%)$} \\
\hline & $\mathrm{E}$ & Standard deviation & $\mathrm{E}$ & Standard deviation & Test cycle $(\mathrm{min})$ & \\
\hline EX 2 & 95.00 & 1.27 & 96.33 & 2.82 & - & 1 \\
\hline EX 1 & 99.70 & 1.27 & 97.29 & 2.85 & 12 & 2 \\
\hline SA 1 & 84.50 & 0.92 & 87.00 & 2.55 & 8 & 3 \\
\hline SA 2 & 83.67 & 0.92 & 84.51 & 2.47 & 5 & 1 \\
\hline NO 1 & 69.43 & 0.34 & 71.86 & 2.10 & 5 & 3 \\
\hline NO 2 & 93.83 & 1.07 & 92.15 & 2.70 & 6 & 2 \\
\hline FV 2 & 77.40 & 2.65 & 80.66 & 2.36 & 8 & 4 \\
\hline FV3 & 75.70 & 0.83 & 76.10 & 2.23 & 5 & 1 \\
\hline MG 1 & 87.27 & 1.67 & 77.21 & 2.26 & 4 & 12 \\
\hline
\end{tabular}

$6.5 \mathrm{~min}$, which demonstrates the agility of the procedure, while for uniaxial compression, this average time is around 45 minutes (Table 4).

Figure 4 shows the determined values of Young's modulus (E flex). The low values of standard deviation in the IET $(<2.85 \mathrm{GPa})$ indicate that the measurements presents adequate repeatability.

The IET measurements were much faster than a traditional measurement using the static method, which takes around 2 hours, since the interval between measurements was $6 \pm 1.4 \mathrm{~min}$.

Young's modulus of basalts and diabases (Figure 4) agrees with those reported in the literature. For basalts, Aadnoy and Looyyeh (2014) found values ranging from 1.2 to $83.8 \mathrm{GPa}$ and Caputo and Caputo [25] reported values of $100 \mathrm{GPa}$. For diabases, Lambe and Whitman [26] found values ranging from 86.87 to $116.52 \mathrm{GPa}$ and Jaeger and Cook [27] reported values around $99.28 \mathrm{GPa}$.

Young's modulus of the EX, SA, and FV samples is very close and slightly differs from the values found for $\mathrm{NO}$ samples (Figure 4). These discrepancies can be explained by the difference in the direction of the sample drawn, sampling at distinct points of the mine, and eventual presence of fractures in the specimen.

Figure 5 shows the expected tendency of increase of Young's modulus (determined by both methods IET and

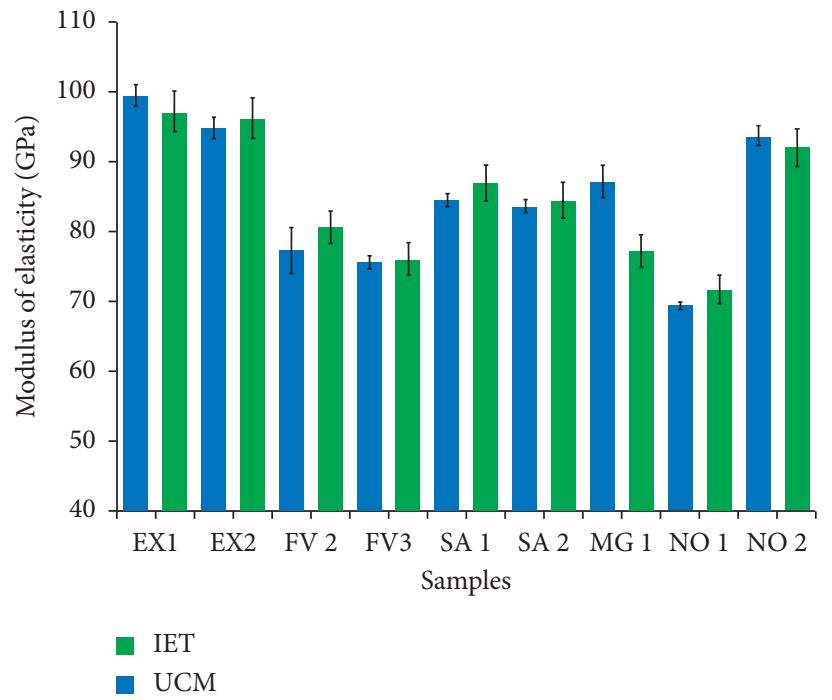

FIGURE 4: Elasticity modulus determined by UCM and IET and the standard deviation.

UCM) as the density increases. Such relation has been reported for materials like bone [28], nanoporous self-assembled silicas [29], and self-sealed $\mathrm{Si}_{3} \mathrm{~N}_{4} / \mathrm{BN}$-based 


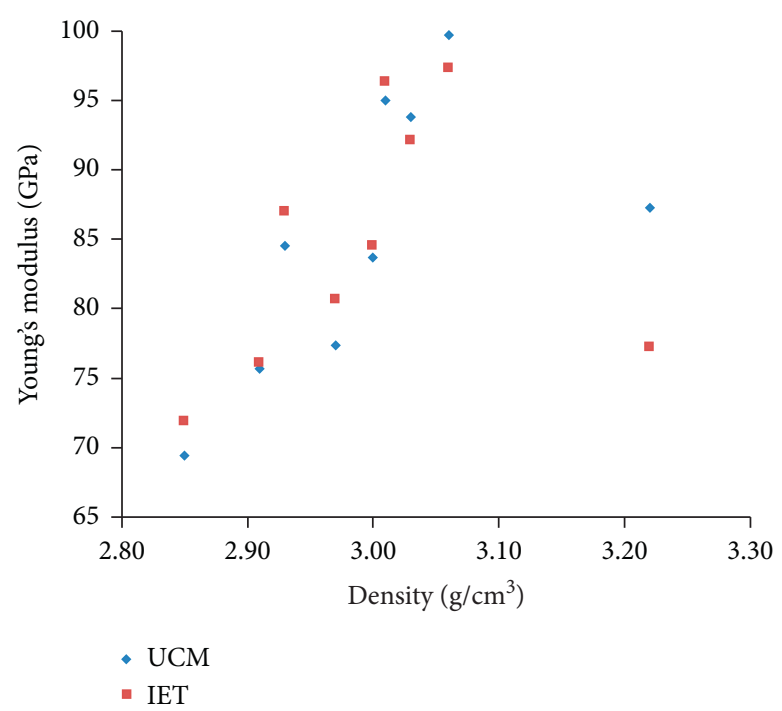

Figure 5: Density x Young's Modulus by IET and UCM.

TABLE 5: Costs for conducting Young's modulus assays by pulse excitation and uniaxial compression methods.

\begin{tabular}{|c|c|c|c|}
\hline Test & Description & $\begin{array}{c}\text { Cost per } \\
\text { sample } \\
(1 \text { test })(\mathrm{R} \$)\end{array}$ & $\begin{array}{c}\text { Cost per } \\
\text { sample } \\
(10 \text { tests })(\mathrm{R} \$)\end{array}$ \\
\hline IET & $\begin{array}{c}\text { Characterization of Young's modulus }(E) \text { by the flexural vibration mode or by the } \\
\text { longitudinal vibration mode }\end{array}$ & 200.00 & 100.00 \\
\hline IET & $\begin{array}{c}\text { Characterization of Young's modulus }(E) \text { by the flexural and longitudinal vibration } \\
\text { modes }\end{array}$ & 250.00 & 150.00 \\
\hline $\begin{array}{l}\text { Uniaxial } \\
\text { compression }\end{array}$ & Uniaxial compression test with Young's modulus determination & 890.00 & 890.00 \\
\hline
\end{tabular}

laminated structures [30]. Krstic and Krstic [30], for instance, found that any small decrease in the density of $\mathrm{Si}_{3} \mathrm{~N}_{4} /$ $\mathrm{BN}$ led to a large decrease in Young's modulus. The MG sample $\left(\right.$ density $=3.22 \mathrm{~g} / \mathrm{cm}^{3}$ ), however, does not follow this tendency, probably due to experimental differences during Young's modulus determination.

Table 5 shows the budgets elaborated between March 18 and 22, 2019, for flexural and/or longitudinal vibration IET tests compared to the standard uniaxial compression test. Vibration methods are cheaper than the compression method. In addition, there is little variation in the cost of determining Young's modulus by the vibration methods.

The values presented in Table 5 show that for one to nine tests in the IET, the costs are about $22.5 \%$ of the UCM, and when the number of tests are higher than 10, these costs fall to $11.5 \%$.

It must be emphasized that the execution of the tests through the IET method is safe because, since it is not destructive, there is no generation of fragments in the case of the rupture of the sample. The preservation of the test specimen is important for possible reproduction of the experiments and confirmation of the results.

Therefore, IET and the sonelastic are innovative promising techniques for the determination of Young's modulus of several materials, in comparison with the static method, since the execution of the measurement is faster, cheaper, and safer. The accuracy in determining Young's modulus is an advantage for the calculation of the blastability index, ensuring reliability to the evaluation of the mechanical behavior of a rock mass.

\section{Conclusions}

The IET method was suitable for the determination of Young's modulus since the found results presented high repeatability and agreed with those reported in the literature for the same type of materials. In addition, compared to UCM, the results were on average slightly higher (3.39\%) for the IET, which is expected in a comparison between static and nonstatic testing.

The costs for the IET analysis are about 11.5 to $22.5 \%$ of costs involved in the uniaxial compression method, depending the number of tests.

Because it is a nondestructive method, the IET is safer, with no risk of injury by throwing sample fragments and preserving them for future reevaluations.

The time to perform IET testing is about 6.5 minutes, and UCM takes about 45 minutes or more, being about 6.9 times faster.

The work highlighted important advantages of the IET in comparison with the traditional methods such as shorter execution time, higher safety, and nondestruction of the 
sample. The results are satisfactory for the safe use of IET in the acquisition of Young's modulus values.

\section{Data Availability}

There are restrictions on data access because the work is still in progress.

\section{Conflicts of Interest}

There are no conflicts of interest.

\section{Acknowledgments}

The authors are thankful to PPGEM (Programa de PósGraduação em Engenharia Mineral) of UFOP (Universidade Federal de Ouro Preto), PUC-Minas civil Engineering Laboratory Poços de Caldas, ATCP Engenharia Física, and the professors of Federal University of Alfenas, Alexandre Silveira e Daniela Gomes Horta, for their collaboration.

\section{References}

[1] J. S. P. Panitz, Desenvolvimento e implementação de metodologias para a determinação da deformabilidade e tensões em maciços gnáissicos, Pontifícia Universidade Católica Do Rio De Janeiro, Rio de Janeiro, Brazil, 2007.

[2] J. Martínez-Martínez, D. Benavente, and M. A. García-delCura, "Comparison of the static and dynamic elastic modulus in carbonate rocks," Bulletin of Engineering Geology and the Environment, vol. 71, no. 2, pp. 263-268, 2012.

[3] J. L. d. Morais and M. d. F. A. Gripp, "Fundamentos para simulação dos desmontes de rocha por explosivos," Rem: Revista Escola de Minas, vol. 57, no. 4, pp. 241-248, 2004.

[4] A. Hekmat, S. Munoz, and R. Gomez, "Prediction of rock fragmentation based on a modified kuz-ram model," in Proceedings of the 27th International Symposium On Mine Planning And Equipment Selection - MPES 2018, pp. 69-79, Springer International Publishing, New York, NY, USA, 2019.

[5] A. T. Spathis, "A correction relating to the analysis of the original Kuz-Ram model," Fragblast, vol. 8, no. 4, pp. 201-205, 2004.

[6] S. Gheibie, H. Aghababaei, S. H. Hoseinie, and Y. Pourrahimian, "Modified kuz-ram fragmentation model and its use at the sungun copper mine," International Journal of Rock Mechanics and Mining Sciences, vol. 46, no. 6, pp. 967-973, 2009.

[7] M. T. P. A. Augusto Cesar da Silva Bezerra, F. M. Silva, and M. M. N. de Souza Soares, "Relações do módulo de elasticidade dinâmico, estático e resistência à compressão do concreto," Anais do $51^{\circ}$ Congresso Brasileiro do Concreto-IBRACON, vol. 20, 2009, https://www.researchgate.net/publication/ 311982870_Relacoes_do_modulo_de_elasticidade_dinamico_ estatico_e_resistencia_a_compressao_do_concreto.

[8] J. C. A. Garaygordobil, Dynamic Assessment of Structural Building Components, Ph.D. thesis, SERC, Barcelona, Spain, 2003.

[9] E. V. M. Carrasco, C. B. Vargas, M. d. F. Souza, and J. N. R. Mantilla, "Avaliação das características mecânicas da madeira por meio de excitação por impulso," Physical Review Materials, vol. 22, 2017.

[10] M. F. Slim, A. Alhussein, F. Sanchette, B. Guelorget, and M. François, "An enhanced formulation to determine young's and shear moduli of thin films by means of Impulse Excitation Technique," Thin Solid Films, vol. 631, pp. 172-179, 2017.

[11] S. Tognana, W. Salgueiro, A. Somoza, and A. Marzocca, "Measurement of the young's modulus in particulate epoxy composites using the impulse excitation technique," Materials Science and Engineering: A, vol. 527, no. 18-19, pp. 4619-4623, 2010.

[12] D. S. Paolino, H. Geng, A. Scattina, A. Tridello, M. P. Cavatorta, and G. Belingardi, "Damaged composite laminates: assessment of residual young's modulus through the impulse excitation technique," Composites Part B: Engineering, vol. 128, pp. 76-82, 2017.

[13] B. J. Zadler, J. H. L. Le Rousseau, J. A. Scales, and M. L. Smith, "Resonant ultrasound spectroscopy: theory and application," Geophysical Journal International, vol. 156, no. 1, pp. 154-169, 2004.

[14] E. F. ATCP, "Módulos elásticos: visão geral e métodos de caracterização," 2016, https://www.sonelastic.com/pt/fundamentos/ bases/modulos-elasticos.html.

[15] L. B. Otani and A. H. A. Pereira, Determinação do módulo de elasticidade do concreto empregando a Técnica de Excitação por Impulso, ATCP Engenharia Física, Ribeirão Preto, Brazil, 2017.

[16] E. F. ATCP, “A técnica de excitação por impulso,” 2016, https:// www.sonelastic.com/pt/fundamentos/bases/tecnica-excitacaoimpulso.html.

[17] B. M. Horst-Dieter Tietz, M. Dietz, and L. Bühling, "Nondestructive testing of green ceramic materials," 1997, https:// www.ndt.net/article/ecndt98/material/173/173.htm.

[18] ASTM Standard E1876, Dynamic Young 'S Modulus, Shear Modulus, and Poisson' $S$ Ratio by Impulse Excitation of Vibration, ASTM, West Conshohocken, PA, USA, 2015.

[19] ASTM Standard E1875, Standard Test Method for Dynamic Young's Modulus, Shear Modulus, and Poisson's Ratio by Sonic Resonance, ASTM lnternational, West Conshohocken, PA, USA, 2013.

[20] ASTM Standard C215, Standard Test Method for Fundamental Transverse, Longitudinal, and Torsional Resonant Frequencies of Concrete Specimens, ASTM standard, West Conshohocken, PA, USA, 2008.

[21] ASTM Standard D2938, Standard Test Method for Unconfined Compressive Strength of Intact Rock, ASTM standard, West Conshohocken, PA, USA, 2014.

[22] ASTM Standard D4543, Standard Practices for Preparing Rock Core Specimens and Determining Dimensional and Shape Tolerances, ASTM standard, West Conshohocken, PA, USA, 2001.

[23] Suggested methods for determining sound velocity," International Journal of Rock Mechanics and Mining Sciences and Geomechanics Abstracts, vol. 15, no. 2, pp. 53-58, 1978.

[24] S. Montecinos, S. Tognana, and W. Salgueiro, "Determination of the Young's modulus in CuAlBe shape memory alloys with different microstructures by impulse excitation technique," Materials Science and Engineering: A, vol. 676, pp. 121-127, 2016.

[25] A. N. C. Homero Pinto Caputo, Mecânica dos solos e suas aplicações: mecânica das rochas, fundações e obras de terra, LTC, Rio de Janeiro, Brazil, 7th edition, 2015.

[26] T. W. Lambe and R. V. Whitman, Soil Mechanics, Wiley, Hoboken, NJ, USA, 1969.

[27] J. C. John, C. Jaeger, N. G. W. Cook, and R. W. Zimmerman, Fundamentals of Rock Mechanics, Blackwell Publication, Hoboken, NJ, USA, 2007.

[28] M. Vanleene, C. Rey, and M.-C. Ho Ba Tho, "Relationships between density and young's modulus with microporosity and 
physico-chemical properties of wistar rat cortical bone from growth to senescence," Medical Engineering \& Physics, vol. 30, no. 8, pp. 1049-1056, 2008.

[29] H. Fan, C. Hartshorn, T. Buchheit et al., "Modulus-density scaling behaviour and framework architecture of nanoporous self-assembled silicas," Nature Materials, vol. 6, no. 6, pp. 418-423, 2007.

[30] Z. Krstic and V. D. Krstic, "Young's modulus, density and phase composition of pressureless sintered self-sealed Si3N4/ BN laminated structures," Journal of the European Ceramic Society, vol. 28, no. 8, pp. 1723-1730, 2008. 